\title{
Biofilm Development, Plant Growth Promoting Traits and Rhizosphere Colonization by Pseudomonas entomophila FAP1: A Promising PGPR
}

\author{
Firoz Ahmad Ansari, Iqbal Ahmad* \\ Biofilm Research Lab., Department of Agricultural Microbiology, Faculty of Agricultural Sciences, Aligarh Muslim University, \\ Aligarh, India \\ Email: *ahmadiqbal8@yahoo.co.in
}

How to cite this paper: Ansari, F.A. and Ahmad, I. (2018) Biofilm Development, Plant Growth Promoting Traits and Rhizosphere Colonization by Pseudomonas entomophila FAP1: A Promising PGPR. Advances in Microbiology, 8, 235-251. https://doi.org/10.4236/aim.2018.83016

Received: January 15, 2018

Accepted: March 26, 2018

Published: March 30, 2018

Copyright (c) 2018 by authors and Scientific Research Publishing Inc. This work is licensed under the Creative Commons Attribution International License (CC BY 4.0).

http://creativecommons.org/licenses/by/4.0/

(c) (i) Open Access

\begin{abstract}
Among the diverse soil bacteria, plant growth promoting rhizobacteria (PGPR) mark an important role in enhancing plant growth through a range of beneficial functions. This is mainly achieved by effective rhizosphere colonization by PGPR. Biofilm development by PGPR is considered as a survival strategy over the planktonic mode of growth under stress and natural conditions. Since the performance of microbial inoculants under field conditions is not always consistent due to various biotic and abiotic factors affecting survival, colonization and functions. Therefore, the rhizobacteria with efficient colonization ability and exhibiting multiple PGP traits are expected to perform better. We hypothesized that the biofilm forming ability of PGPR on plant root will be an added advantage to rhizosphere colonization. Therefore, we have selected a promising isolate of PGPR through random screening programme from rhizoplane of wheat (Triticum aestivum). The selection was based on biofilm development ability, multifarious PGP activities (production of indole acetic acid, siderophore, phosphate solubilization, hydrogen cyanide, ammonia production and biocontrol activity) and tolerance to salinity and heavy metals. The selected isolate was identified by $16 \mathrm{~s}$ rRNA partial gene sequencing as Pseudomonas entomophila-FAP1. The strain FAP1 formed strong biofilm in microtitre plate, glass surface as well as on the roots of wheat seedlings. Biofilm forming capacity of the FAP1 was characterized by scanning electron microscopy and confocal laser scanning microscopy. FAP1 exhibited biofilm-related traits such as the production of exopolysaccharides, EPS $\left(1501.33 \pm 1.08 \mu \mathrm{g} \mathrm{ml}^{-1}\right)$, alginate $\left(212.81 \pm 1.09 \mu \mathrm{g} \mathrm{ml}^{-1}\right)$, swarming motility $(22 \pm 1.36 \mathrm{~mm})$, swimming motility $(31 \pm 2.12 \mathrm{~mm})$ and cell surface hy-
\end{abstract}


drophobicity (63\%). Rhizosphere colonization by FAP1 was found $7.5 \log$ $\mathrm{CFU} \mathrm{g}{ }^{-1}$ of soil comparable with rhizoplane colonization (7.2 $\mathrm{Log} \mathrm{CFU} \mathrm{g}^{-1}$ of root). Therefore, biofilm formation on plant roots by promising PGPR may be included as an additional criterion to select a better rhizosphere colonizer. Further, study with mutant deficient in biofilm should be developed for comparative study to explore the exact contribution of biofilm in root colonization under natural soil-plant system.

\section{Keywords}

Biofilm, PGPR, Rhizosphere Colonization, Pseudomonas entomophila, SEM, and CLSM

\section{Introduction}

Biofilm development by rhizobacteria is considered as a common mode of lifestyle under the natural condition and provided protection to a number of biotic and abiotic stress conditions. The interaction among various plant growth promoting rhizobacteria has been explored mainly under the planktonic mode of growth. However, understanding on the behavior of PGPR in biofilm mode on the root surface and soil is still in the stage of infancy. Majority of the rhizobacteria are capable of forming biofilm in vitro but root-associated biofilm in situ has yet to be explored as the conditions are different in the soil-plant root system. Therefore an in-depth investigation of the biofilm development on root surface and rhizosphere colonization is needed to improve the understanding of plant-microbe interaction. Biofilms are bacterial communities enclosed within self-produced extracellular polymeric substances (EPS). In nature, biofilm constitutes a protected growth modality allowing bacteria to survive in hostile environment. Various traits which are associated directly or indirectly to the biofilm development includes EPS production, swarming and swimming motility, cell surface hydrophobicity and alginate production in Pseudomonas sp. and other bacteria [1].

The biofilm may influence resource competition or production of inhibitory compounds and increase resistance to abiotic stresses [2]. Beneficial plant growth promoting rhizobacteria (PGPR) associated with plant root surfaces are known to contribute towards increase in plant yield [3]. The mechanisms of plant growth promotion by various PGPR has been well documented by both direct (production of plant hormones, nitrogen fixation, phosphate solubilization and sequestering iron) and indirect (antibiotics and lytic enzymes, induced resistance, HCN production and competition) mechanisms [4] [5] [6]. However, environmental factors influencing the survival and rhizosphere colonization played a key role in ensuring consistency in the performance of PGPR. The role of biofilm has been documented in maintaining ecological balance and plant growth in the natural soil [7] and, compared with planktonic counterparts, conferred benefits such as increased resistance to antibacterial compounds, en- 
hanced protection from desiccation and protozoan predation and elevated rates of horizontal gene transfer [8] [9] [10]. The PGPR are known to adhere or colonize in the rhizosphere and stimulate the growth of plants and suppress plant diseases. [11]. There is evidence indicating that inoculation with biofilm-forming PGPR has better plant growth promotion as compared to non-biofilm former inoculants [12]. In another study, [13] demonstrated that the resistance mechanism provided through biofilm mode of growth protected plant from stress condition. Considering the role of biofilm as a bacterial survival strategy, we hypothesized that a promising PGPR strain exhibiting strong ability to form biofilm might be an effective root/rhizosphere colonizer. In this study a promising new isolate of Pseudomonas sp. FPA1 was selected to assess its biofilm development and rhizosphere colonization ability to be exploited as promising PGPR for wheat.

\section{Materials and Methods}

\subsection{Bacterial Strains and Their Characteristics}

Rhizoplane of wheat (Triticum aestivum) was collected aseptically and kept in sterile polybag before isolating Pseudomonas sp. on Kings B agar medium (Hi-media) containing per liter of distilled water: $10 \mathrm{~g}$ proteose peptone, $10 \mathrm{ml}$ glycerol, $1.5 \mathrm{~g} \mathrm{~K}_{2} \mathrm{HPO}_{4}, 1.5 \mathrm{~g} \mathrm{MgSO}_{4}, 20 \mathrm{~g}$ agar, $\mathrm{pH}$ 7.2. Colonies exhibiting characteristics of Pseudomonas sp. were selected and purified. The suspected culture was subjected to cultural and biochemical characteristics before assigning an isolate number for preservation and further identification. Promising Pseudomonas isolates were selected for our lab culture collection. One of the promising isolate FAP1 was subjected to molecular identification by $16 \mathrm{~s}$ rRNA partial gene sequence analysis. The identified isolate was further used in this study. $\mathrm{Nu}$ trient broth/agar (Hi-media) was used to culture test isolates.

\subsection{Screening Assay for PGP Attributes}

Qualitative estimation of Indole acetic acid production (IAA) was detected by the method of [14]. Method of [15] as adopted by [5] was used for quantitative estimation of IAA production in the presence of $500 \mu \mathrm{g} \mathrm{ml}^{-1}$ tryptophan. Ammonia production in peptone water was done by using the method of [16]. Production of hydrogen cyanide among test isolates was screened using the method of [17]. Quantitative estimation of siderophore was estimated adapting the method of [18]. Qualitative estimation of phosphate solubilization was done by observing a halo zone around the bacterial colony growing in Pikovskaya medium [19]. Solubilization of tricalcium phosphate in liquid medium quantitatively was performed as described earlier [5]. Antifungal activity was determined by observing clear zone around bacterial colony growing in Potato dextrose agar medium (Hi-media) [20].

\subsection{Tolerance to Salt ( $\mathrm{NaCl})$, Heavy Metals and Antibiotics}

To determine the salt tolerance of the test isolates, they were cultured in KB 
broth (King et al. 1994) supplemented with $25-800 \mathrm{mM}$ salt $(\mathrm{NaCl})$ concentrations and kept at $28^{\circ} \mathrm{C} \pm 2^{\circ} \mathrm{C}$ for $48 \mathrm{~h}$. The growth was observed after $48 \mathrm{~h}$ of incubation. The test isolates were tested for tolerance to heavy metals by agar plate dilution method using nutrient agar medium treated separately with increasing concentrations ( $0-1600 \mu \mathrm{g} \mathrm{ml}^{-1}$; at a two-fold dilution interval) each of $\mathrm{Cu}$ $\left(\mathrm{CuSO}_{4} \cdot 5 \mathrm{H}_{2} \mathrm{O}\right), \mathrm{Cd}\left(\mathrm{CdCl}_{2}\right), \mathrm{Cr}\left(\mathrm{K}_{2} \mathrm{Cr}_{2} \mathrm{O}_{7}\right), \mathrm{Zn}\left(\mathrm{ZnCl}_{2}\right)$ and $\mathrm{Pb}\left(\mathrm{PbCl}_{2}\right)$ were spot inoculated with $10 \mu \mathrm{l}$ of $10^{8}$ cells ml ${ }^{-1}$. Plates were incubated at $28^{\circ} \mathrm{C} \pm 2^{\circ} \mathrm{C}$ for 48 $\mathrm{h}$ and the highest concentration of each metal supporting bacterial growth was defined as maximum tolerance level (MTL). Antibiotic sensitivity was assayed by disc diffusion method using Muller Hinton agar medium. Briefly, $100 \mu \mathrm{l}$ of freshly grown and appropriately diluted culture $10^{7} \mathrm{CFU} \mathrm{ml}{ }^{-1}$ was spread and antibiotic disc were placed on plates and incubated at $28^{\circ} \mathrm{C} \pm 2^{\circ} \mathrm{C}$ for $48 \mathrm{~h}$. sensitivity to antibiotic was measured by measuring the zone of inhibition around disc.

\subsection{Quantitative Estimation of Exopolysaccharides (EPS) Production}

EPS extraction and quantitation were performed as described by [21]. The pre-inoculum was grown in $\mathrm{KB}$ broth (Hi-media) for Pseudomonas entomophila FAP1 for overnight at $28^{\circ} \mathrm{C} \pm 2^{\circ} \mathrm{C}$. The volume of $500 \mu \mathrm{l}$ of pre-inoculum was added in fresh $50 \mathrm{ml}$ culture medium and allow to grow at $28^{\circ} \mathrm{C} \pm 2^{\circ} \mathrm{C}$ for five days at $120 \mathrm{rpm}$ in the rotatory shaking incubator. The culture volume of $200 \mathrm{ml}$ was centrifuged at $800 \mathrm{rpm}$ for $20 \mathrm{~min}$ at $4^{\circ} \mathrm{C}$. The supernatant was filtered through nitrocellulose filter with the pore size of $0.45 \mu \mathrm{m}$ (Millipore filter, Bangalore, India). From the final filtrate, EPSs were precipitated after the addition of three volumes of chilled ethanol and the solution was kept at $4^{\circ} \mathrm{C}$ for overnight for precipitation of exopolysaccharides. The weight of the precipitated EPS was measured after drying at $80^{\circ} \mathrm{C}$ for $48 \mathrm{~h}$.

\subsection{Alginate Quantification Assay}

Alginate extraction in test isolates was performed with $48 \mathrm{~h}$ grown culture. After incubation, the culture was centrifuged at $10,000 \mathrm{rpm}$ for $10 \mathrm{~min}$ and cell-free supernatant was collected. Isolation of deacetylated alginate from culture supernatants was performed by adding an equal volume of isopropanol and kept it for one day under static conditions. The precipitate was collected by centrifugation $10,000 \mathrm{rpm}$ for $10 \mathrm{~min}$. The resultant pellet was washed successively with $1 \mathrm{ml}$ of $70 \%$ and $96 \%$ ethanol. The pellet was dried at $37^{\circ} \mathrm{C}$ for $15 \mathrm{~min}$ and dissolved in 1 $\mathrm{ml}$ of sterile $\mathrm{ddH}_{2} \mathrm{O}$. For quantification, $100 \mu \mathrm{l}$ of the suspension was transferred to fresh test tubes and volume was made up to $1 \mathrm{ml}$ with Milli-Q water. One $\mathrm{ml}$ of freshly prepared borate sulfuric acid solution was added followed by $30 \mu \mathrm{l}$ of fresh carbazole reagent and mixed thoroughly. The mixture was kept for $15 \mathrm{~min}$ at room temperature and the absorbance was measured at $500 \mathrm{~nm}$ against a reagent blank and calculated in terms of $\mu \mathrm{g} / \mathrm{mg}$ wet biomass [22]. Every assay was repeated in triplicate at least three times. 


\subsection{Cell Surface Hydrophobicity Assay}

Cell surface hydrophobicity ( $\mathrm{CSH}$ ) was quantified by the using microbial adhesion assay to hydrocarbons (MATH) as described by [23]. Bacterial cultures were incubated in NB broth and hydrophobicity was determined after $1^{\text {st }}, 2^{\text {nd }}$ and $4^{\text {th }}$ day of incubation. To evaluate the percentage of hydrophobicity, $5 \mathrm{ml}$ of $24 \mathrm{~h}$ grown culture was centrifuged at $8000 \mathrm{rpm}$ for $10 \mathrm{~min}$ and pellets were resuspended in phosphate-magnesium buffer $(\mathrm{pH}=7.4)$, and read the absorbance at $400 \mathrm{~nm}$ using UV-vis spectrophotometer [Shimadzu UV-vis spectrophotometer$8500 \mathrm{II}$ ] called initial bacterial suspension. Five $\mathrm{ml}$ of culture was added to $0.2 \mathrm{ml}$ of hexadecane and mixed vigorously with the help of cyclomixer. After separating the aqueous phase, absorbance was determined at $400 \mathrm{~nm}$ called as final concentration in the aqueous phase. The percentage of hydrophobicity was calculated as follows:

$$
\text { Percent hydrophobicity }(\%)=\left[1-\left(A_{1} / A_{0}\right)\right] * 100
$$

where $A_{1}$ is initial bacterial suspension absorbance and $A_{0}$ is absorbance of the aqueous phase.

\subsection{Swimming and Swarming Motility Assay}

Swimming and swarming motility assay was performed according to the method adopted by [24]. Adler (1966). Assay plates containing Nutrient broth medium with $0.3 \%$ and $0.5 \%(\mathrm{w} / \mathrm{v})$ agar were used for swimming and swarming motility assay respectively. Each assay plate was spot inoculated with $3 \mu \mathrm{l}$ of the freshly grown bacterial culture of cell density of $\left(10^{7}\right.$ cells $\left.\mathrm{ml}^{-1}\right)$. The inoculated plates were sealed with the help of parafilm to prevent dehydration and incubated at $28^{\circ} \mathrm{C} \pm 2^{\circ} \mathrm{C}$ temperature for $48 \mathrm{~h}$. Swimming and swarming motilities were then determined by measuring the swarm diameter after $24 \mathrm{~h}$ and $48 \mathrm{~h}$ and expressed the zone in millimeters.

\subsection{Biofilm Quantification by Use of Crystal Violet Assay}

In vitro biofilm quantification was performed by using the method of [25]. Bacteria were grown overnight on Nutrient agar (NA) plate was resuspended in NB medium and diluted to the final optical density at $600 \mathrm{~nm}$ of 0.02 , bacterial cultures were transferred to 96 well polystyrene plate. The volume of culture was $160 \mu \mathrm{l}$ per well. The cultures were allowed to stand at $28 \pm 2^{\circ} \mathrm{C}$ for $48 \mathrm{~h}$. The quantification of biofilm formation was assayed by the staining with $0.1 \%$ crystal violet. After the growth period wells of the microtitre plate was emptied and wash gently with double distilled water at least three times to remove loosely attached bacterial cells and left at room temperature for $30 \mathrm{~min}$. Samples were stained by the addition of the $200 \mu \mathrm{l}$ of the $0.1 \%$ crystal violet solution to each well and incubated at $28^{\circ} \mathrm{C}$ for $20 \mathrm{~min}$. The wells of plates were then washed. The intensity of crystal violet staining was measured after addition of $70 \%$ ethanol to each dry well. The samples were incubated for $20 \mathrm{~min}$, after which the 
absorbance was measured at $590 \mathrm{~nm}$ on ELISA plate reader (Thermo Scientific Multiskan EX, UK). Biofilm quantification were tested in five independent wells.

The data were statistically analyzed by analysis of variance test (SPSS version 17.0 for Windows; SPSS Inc., Chicago, IL, USA).

\subsection{Bacterial Seed Treatment on Germination and Vigour Index in Wheat}

In order to determine the effect of the isolates on germination and seedling vigour, twenty seeds of wheat inoculated with each isolate were incubated in $9-\mathrm{cm}$ petri dishes on two layers of moistened filter paper. As a control treatment, seeds treated with water instead of bacterial inoculum were also observed. In order to maintain sufficient moisture for germination, $5 \mathrm{ml}$ distilled water was added to the petri dishes every other day and seeds were incubated in climate control growth chamber. The germination percentage was recorded every $24 \mathrm{~h}$ for 7 days. Root and shoot length were measured after seventh day. The experiment was planned as a completely randomized design with five replication for each isolates.

Germination rate $(\%)=$ number of seeds germinated $\div$ total number of seeds $\times 100$

Vigour index $=\%$ germination $\times$ total plant length

\subsection{Biofilm Formation on Glass Surface and Visualization by SEM and CLSM}

Freshly grown Pseudomonas entomophila FAP1 $(2 \mathrm{ml}$ culture and $2 \mathrm{ml}$ nutrient broth) was kept in 12 well tissue culture plate. Sterile glass coverslip $(20 \mathrm{~mm})$ was placed in each well and incubated at $28^{\circ} \mathrm{C} \pm 2^{\circ} \mathrm{C}$ for 24 to $48 \mathrm{~h}$ under static condition. After the incubation period, glass coverslip was washed three times with $1 \mathrm{X}$ phosphate buffer saline ( $\mathrm{pH}$ 7.2) to remove loosely attached cells from the glass surface. The biofilm on the glass surface was fixed using $2.5 \%$ glutaraldehyde (v/v) in 0.1 M phosphate buffer ( $\mathrm{pH} \mathrm{7.2)} \mathrm{for} 4 \mathrm{~h}$. The samples were dehydrated through a graded ethanol series 30\% - 100\% (v/v) and shadowed with gold for viewing under a Scanning Electron Microscope (Model: JOEL, 76510LV, Japan) at University Sophisticated Instrumentation Facility, AMU, Aligarh. For Confocal Laser Scanning Microscopy (CLSM), the biofilm formed on the glass surface as mention above and stained with $0.1 \%$ acridine orange for 20 min and examined. The depth or thickness of biofilm on the glass surface was analyzed by Z-stack analysis.

\subsection{Biofilm Development on Root Surface}

Biofilm development on the root surface of wheat by FAP1 strain, a separate experiment was planned to assess the biofilm. Briefly, after the transplantation of seven days, two to three leaf stage of Triticum aestivum seedling which was dipped in overnight grown culture in the gnotobiotic soil system, plants were uprooted and washed to remove loosely attached cells from the root surface. The 
root samples were fixed in $2.5 \%$ glutaraldehyde $(\mathrm{v} / \mathrm{v})$ in $0.1 \mathrm{M}$ phosphate buffer ( $\mathrm{pH}$ 7.2) for $2 \mathrm{~h}$ according to Smyth et al. 1990, The root samples were dehydrated through a graded ethanol series $(30 \%-100 \%, \mathrm{v} / \mathrm{v})$ and critical point dried in $\mathrm{CO}_{2}$. To prevent tissue damage pressure was released slowly and shadowed with gold $(22 \mathrm{~nm}$ ) before viewing under Scanning Electron Microscope (Model: JOEL, 76510LV, Japan).

\subsection{Rhizoplane and Rhizosphere Colonization}

The method described by [26]. was adapted for root colonization with little modifications. Briefly, sandy-clay-loam soil (250 gm) in an "autoclavable plastic pots" was maintained in a climatic-controlled growth chamber. Plant nutrient solution $10 \%$ (vol/wt) was added to moisten the soil. For root colonization experiment, seven days old aseptically grown wheat seedling which was two to three leaf stage were dipped into overnight grown culture for four hours and transplanted to sterile soil microcosm in small plastic pots and kept in the climate controlled growth chamber. After each day intervals of 1 - 15 days after transplantation (DAT), seedling uprooted and washed gently in sterile double distilled water to remove loosely attached cells from the root surface. Root (1 gm) removed from seedlings and macerated using mortar pestle aseptically and appropriately diluted in sterile normal saline solution (NSS). The CFU was determined by plating $100 \mu \mathrm{l}$ of the sample on nutrient agar plates amended with $30 \mu \mathrm{g} / \mathrm{ml}$ of rifampicin for selective isolation and incubated at $28^{\circ} \mathrm{C} \pm 2^{\circ} \mathrm{C}$ for $48 \mathrm{~h}$. (Zhang et al. 2011). Furthermore, on the same time intervals, $(1,2,3,4,5,6,7,8,9,10,15$ days), the rhizospheric soils were collected which was tightly adhered to the root surface and serially diluted into the normal saline solution (NSS). The volume of $100 \mu$ of each dilution was plated on KB agar medium. Plates were incubated at $28^{\circ} \mathrm{C} \pm 2^{\circ} \mathrm{C}$ for $48 \mathrm{~h}$ and $\mathrm{CFU} / \mathrm{gm}$ of soil was counted.

\subsection{Statistical Analysis}

All experiments were performed at least three times independently with three to five times replication. Statistical analyses were performed using SPSS (Version 17) for LSD calculation and Microsoft Office Excel 2007 used to graphics. Pot experiments were performed in completely randomized design with 3 - 5 replications.

\section{Results}

\subsection{Characterization of Plant Growth Promoting Activities, Biofilm Screening and Identification of Test Bacteria}

The Pseudomonas strains were isolated after enrichment on King's B medium exhibiting characteristics cultural, morphological and fluorescens at $254 \mathrm{~nm}$ under UV-illuminator was selected with smooth edge and convex shape surface and tested isolates reacted negatively to the Gram's reaction. The biochemical characteristics relevant to Pseudomonas sp. has depicted in Table 1. All the iso- 
lated strains were grown at $4{ }^{\circ} \mathrm{C}$ but no growth at $41^{\circ} \mathrm{C}$. Additionally, pseudomonas sp. showed positive result for catalase and oxidase test. Further selected isolates were screened for their multiple PGP activities, tolerance to salt, heavy metals and antibiotics. Based on promising multifarious PGP activities and tolerance to abiotic stresses and biofilm formation, isolate FAP1 was selected for further study. The FAP1 produces Indole acetic acid, siderophore, HCN, phosphate solubilizing, and antifungal activity was also demonstrated. The FAP1 strain had also shown tolerance to heavy metals, antibiotics and salinity stresses. In vitro biofilm development on microtitre plates indicated FAP1 formed a strong biofilm as presented in Table 1 .

Isolate FAP1 was further identified on $16 \mathrm{~S}$ rRNA partial gene sequencing at DNA Sequencing Service (Macrogen Inc., Seoul, South Korea) using universal primers 27F (5'-AGAGTTTGATCMTGGCTCAG-3') and 1492R (5'-TACGGY TACCTTGTTACGACTT-3'). The resulting nucleotide sequence was submitted to the GenBank Sequence Database (accession number KY110949). The phylogenetic tree was constructed from 16 s rRNA sequence showed 99\% similarity with Pseudomonas entomophila.

\subsection{Quantitative Estimation of PGP Attributes}

Quantitative estimation of IAA production in the presence of exogenous supply $\left(500 \mu \mathrm{g} \mathrm{ml}^{-1}\right)$ of tryptophan revealed that highest in Pseudomonas entomophila FAP1 strain $\left(209.25 \pm 1.32 \mu \mathrm{g} \mathrm{ml}^{-1}\right)$. Additionally, other isolates were also showed varying level of the production of IAA as depicted in Table 1.

\subsection{Alginate and EPS Quantification Assay}

Alginate production was found to be highest in the FAP1 strain $(212.81 \pm 1.09$ $\left.\mu \mathrm{g} \mathrm{ml}^{-1}\right)$. However, other isolates also showed varying degree of alginate production as presented in Table 1. Production of exopolysaccharides (EPS) was observed to be more in the FAP1 strain $\left(1501.33 \pm 1.08 \mu \mathrm{g} \mathrm{ml}^{-1}\right)$. However, other isolates were also showed varying level of EPS production (Table 1).

\subsection{Cell Surface Hydrophobicity}

In the present study, Pseudomonas entomophila FAP1 revealed the adhesion to hydrocarbons and hydrophobicity as: $63 \%$. Although rest of the isolates were also assayed for the hydrophobicity and showed varying pattern in their percent adhesion to hydrocarbon as presented in Table 1.

\subsection{Swimming and Swarming Activity}

After $48 \mathrm{~h}$ of the incubation period, we measured the swarm zone of tested isolates. Pseudomonas entomophila FAP1 strain showed the swimming motility that was $31 \pm 2.12 \mathrm{~mm}$ in diameter and swarming motility for FAP1 was observed in the form of swarm zone that was $22 \pm 1.36 \mathrm{~mm}$ in diameter in the FAP1strain. However, other isolates were also revealed variation in their swimming 
Table 1. Characteristics of biofilm forming stress tolerant plant growth promoting Pseudomonas strains under the study.

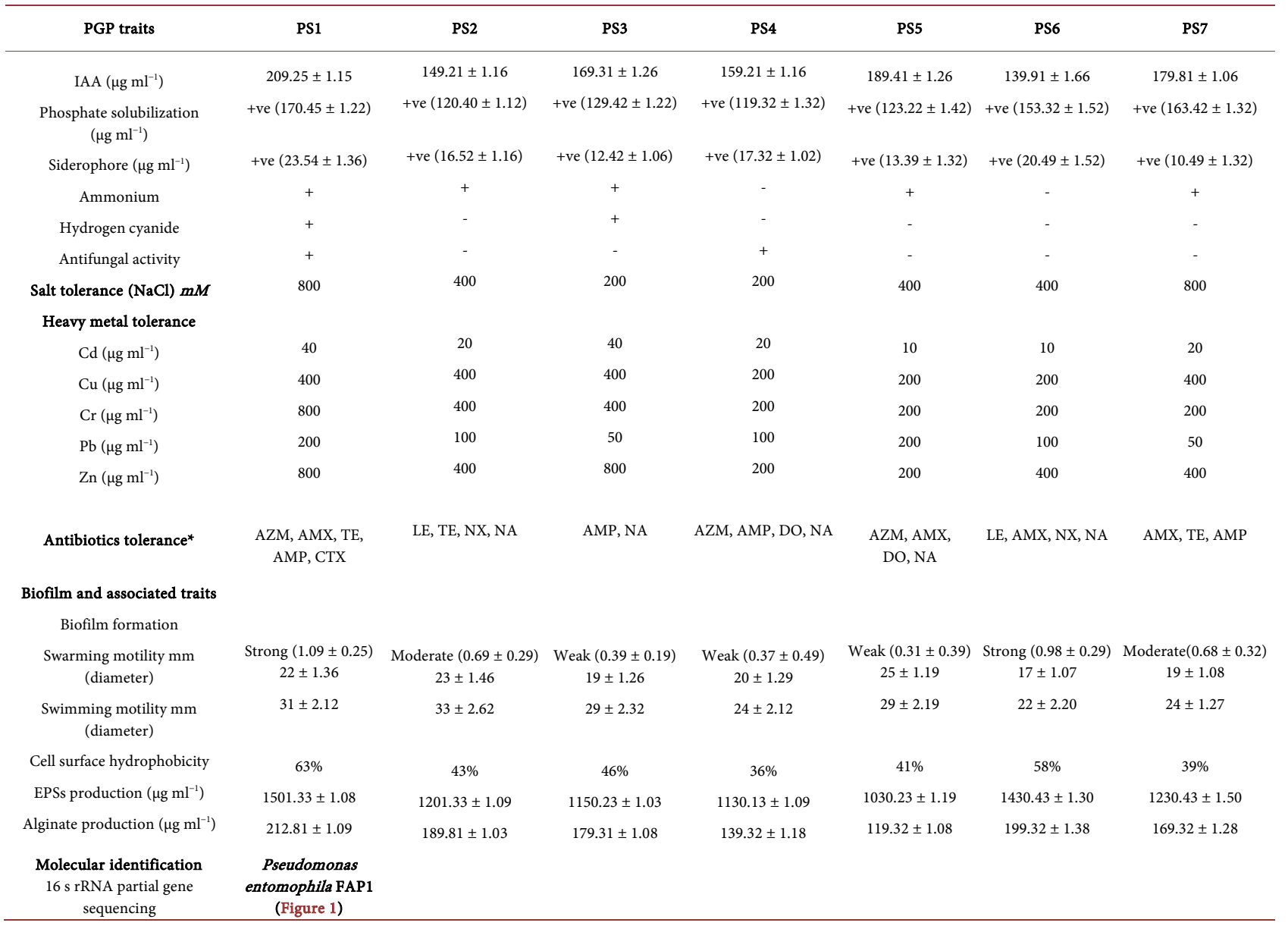

${ }^{*}$ Antibiotics disc potency used as described, Azithromycin (AZM) $30 \mu \mathrm{g}$, Ciprofloxacin (CIP) $30 \mu \mathrm{g}$, Levofloxacin (LE) $5 \mu \mathrm{g}$, Amoxicillin (AMX) $30 \mu \mathrm{g}$, Tetracycline (TE) $30 \mu \mathrm{g}$, Ampicillin (AMP) $2 \mu \mathrm{g}$, Norfloxacin (NX) $10 \mu \mathrm{g}$, Doxycycline (DO) $30 \mu \mathrm{g}$, Nalidixic acid (NA) $30 \mu \mathrm{g}$ and Cefotaxim (CTX) $300 \mu \mathrm{g}$.

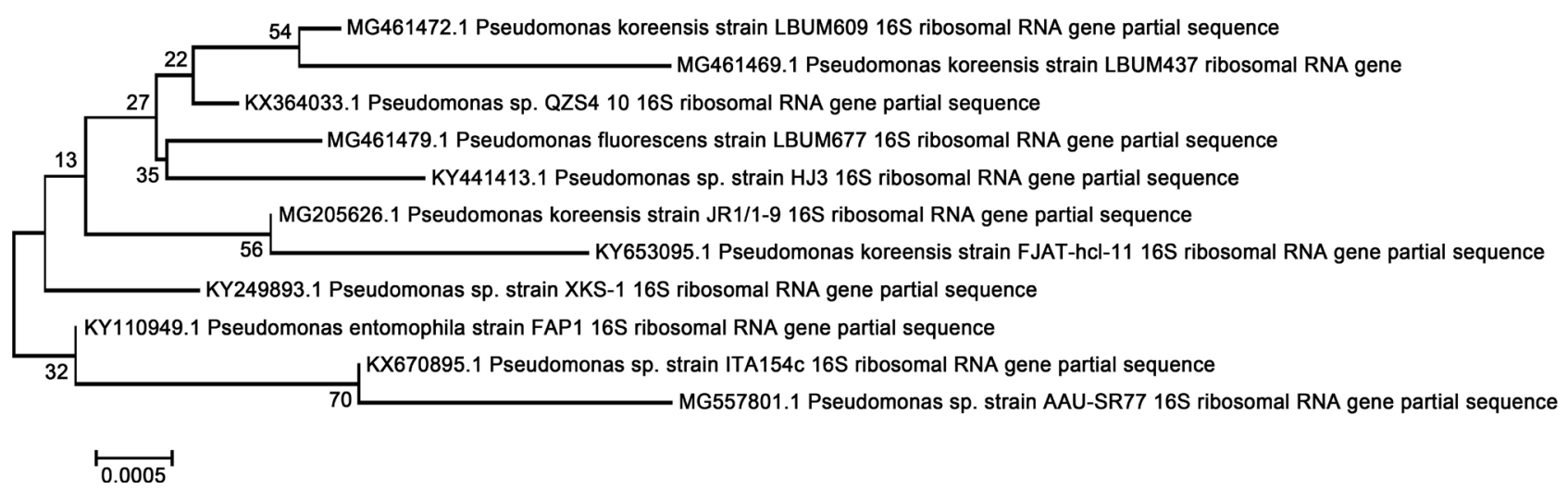

Figure 1. Phylogenetic tree of Pseudomonas entomophila FAP1.

and swarming motility as depicted in Table 1.

\subsection{Microtitre Plate Assay for Biofilm Development}

An assay for biofilm formation was performed on 96 well microtitre plates. In this study, crystal violet assay was used to measure the quantitation of biofilm 
formation [27]. Rhizobacterial strain Pseudomonas entomophila FAP1 showed strong biofilm development on the microtitre plate and optical density measurement was $1.09 \pm 0.25$ of crystal violet at $590 \mathrm{~nm}$. Although, other isolates were also quantified for biofilm development and showed varying level of biofilm forming ability as represented in Table 1.

\subsection{Effect of Bacterial Seed Treatment on Germination and Vigour Index in Wheat}

The effect of rhizobacterial treatment upon seed germination and vigour index of wheat varied with different isolates. The FAP1 strain had a significant effect on germination rate and vigour index over all the tested isolates. Seed germination was increased $84.58 \% \pm 1.25 \%$ and vigour index was $78.25 \% \pm 1.36 \%$ with the treatment of FAP1 compared to uninoculated control. Although, other isolates were also revealed different pattern of seed germination and vigour index as depicted in Figure 2.

\subsection{Biofilm Development on Glass Surface}

An assay for biofilm development on the glass surface was performed in 12 well tissue culture plate. The test bacterium FAP1 was formed strong and very dense biofilm on the glass surface as evident from SEM micrograph depicted in Figure 3. Confocal laser scanning micrograph was also provided evidence of strong biofilm development and thickness of biofilm on the glass surface as depicted in Figure 4(a) and Figure 4(b).

\subsection{Biofilm Formation on Root Surface}

Adherence of bacteria on the root surface of wheat (Triticum aestivum) was visualized after incubating seven days old seedling with the freshly grown culture

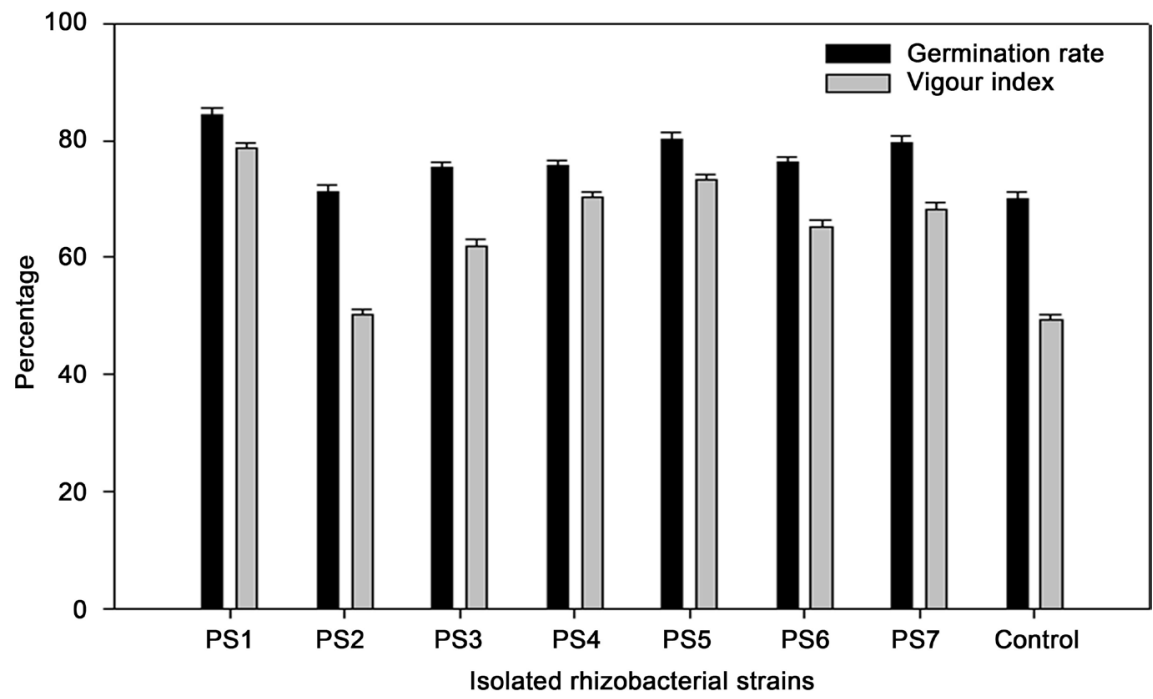

Figure 2. Effect of rhizobacterial treatment on the germination rate and seedling vigour index. 

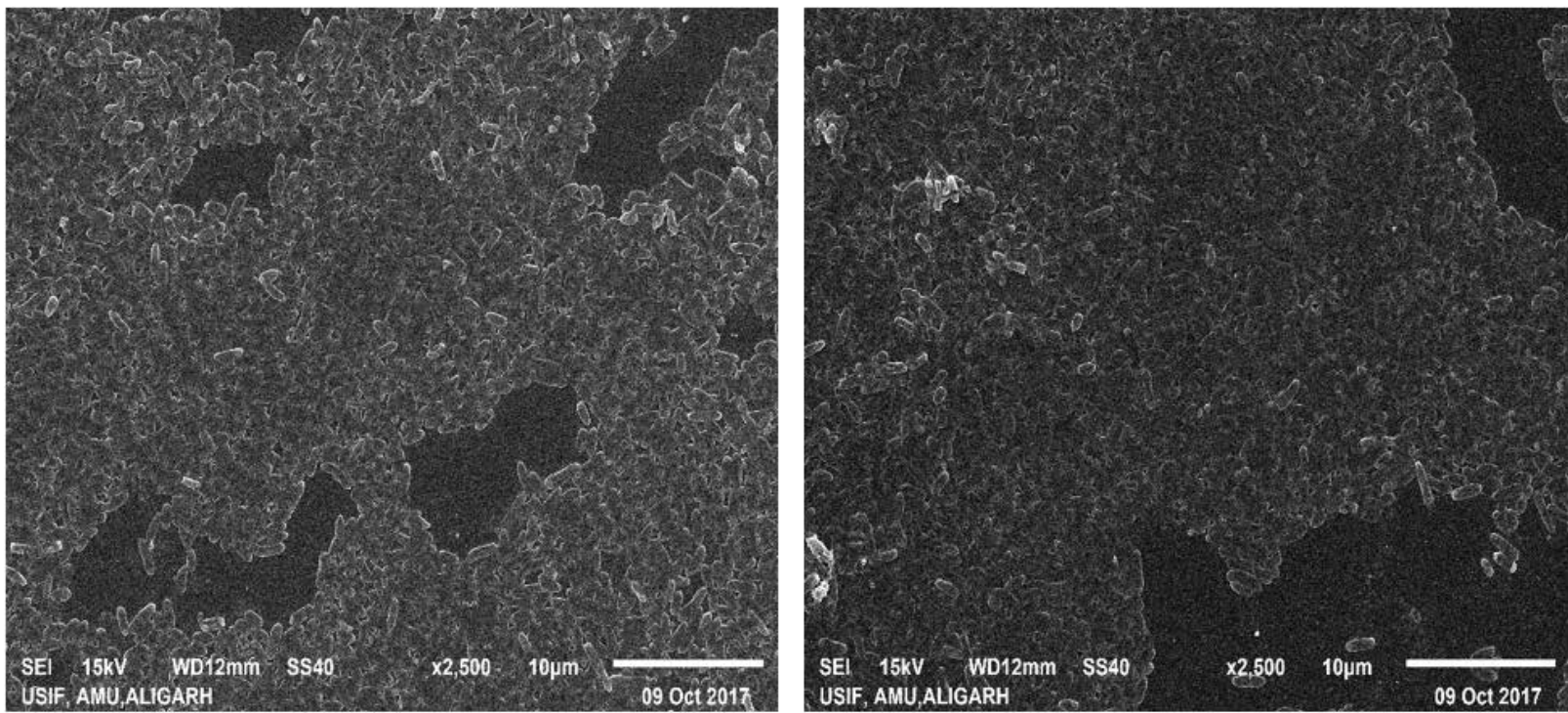

Figure 3. SEM images of biofilm development by Pseudomonas entomophila FAP1 on the glass cover slip.
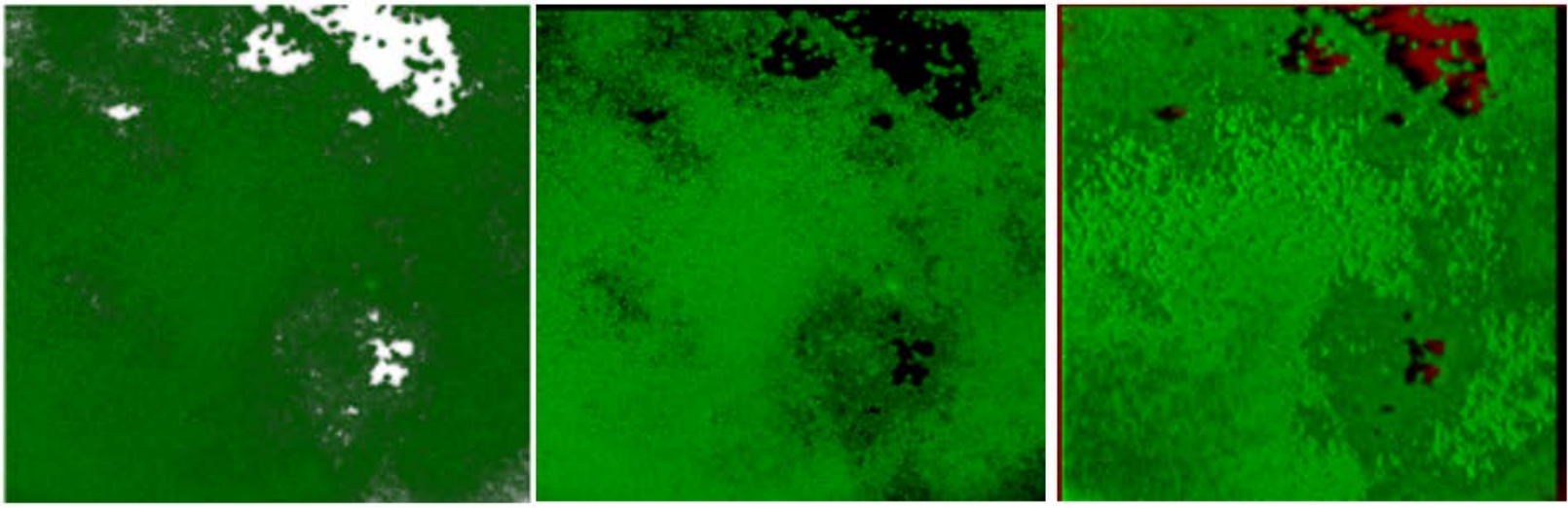

(a)

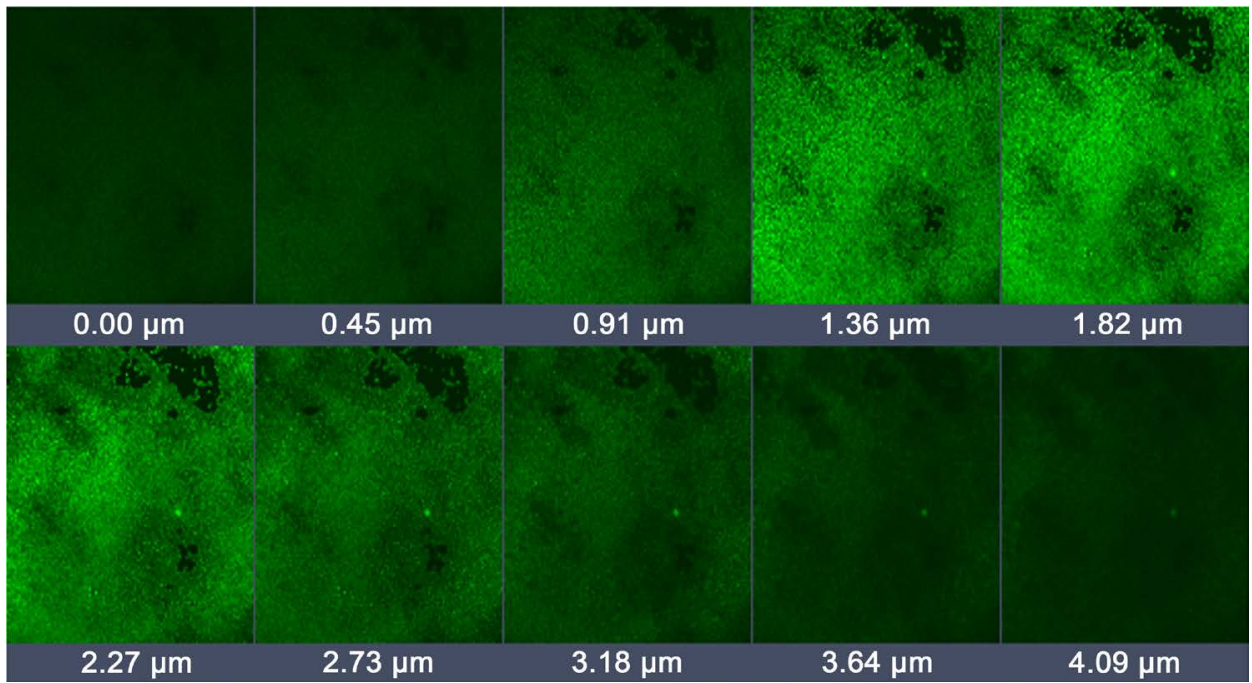

(b)

Figure 4. (a) 3D confocal micrographs of mature biofilm formed by Pseudomonas entomophila on glass coverslip stained by $0.1 \%$ Acridine orange; (b) 3D confocal micrographs of mature biofilm with Z-stacks showing depth of biofilm at different stacks. 
of Pseudomonas entomophila FAP1. It is evident from Figure 5 that test strains attached to the root surfaces in vitro. It was observed that the strain FAP1 attached to the root surface in dense form at a different portion of the root surface and showed strong root colonization in the form of microcolonies/biofilm.

\subsection{Rhizoplane and Rhizosphere Colonization}

The results for the viable count of rhizoplane and rhizosphere during first to fifteen days after transplantation (DAT) were observed. The Pseudomonas entomophila FAP1 strain in the biofilm mode of life on the rhizoplane was maintained up to 15 days. After $24 \mathrm{~h}$ and $48 \mathrm{~h}$ after transplantation, there was drastically altered the structured of preformed biofilm on the root surface that was relocated from the rhizoplane to rhizosphere in the form of colony count. Initial bacterial count of Pseudomonas entomophila FAP1 strain was 7.5 Log CFU/gm of root but when we transplant into the soil system, preformed biofilm on wheat root surface was turned down and detached from rhizoplane from $7.5 \mathrm{Log}$ "CFU/gm" of root to $6.1 \mathrm{Log}$ "CFU/gm" of root Figure 6. We handled the experiment up to
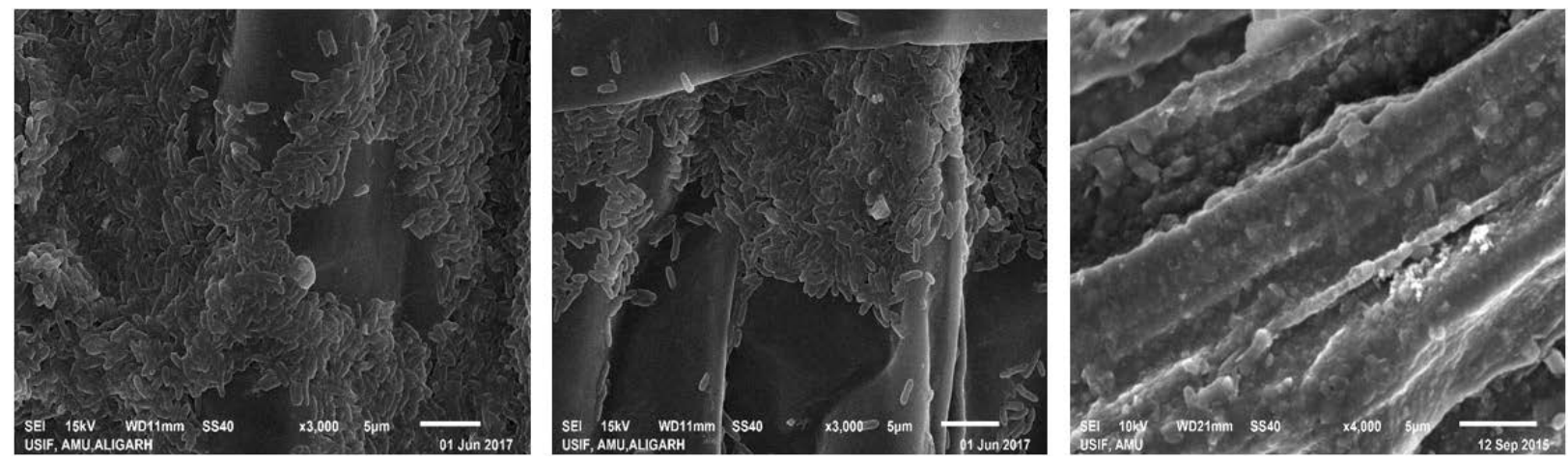

Figure 5. SEM images of biofilm development by Pseudomonas entomophila FAP1 on the root surface of wheat (Triticum aestivum) compared to uninoculated control.

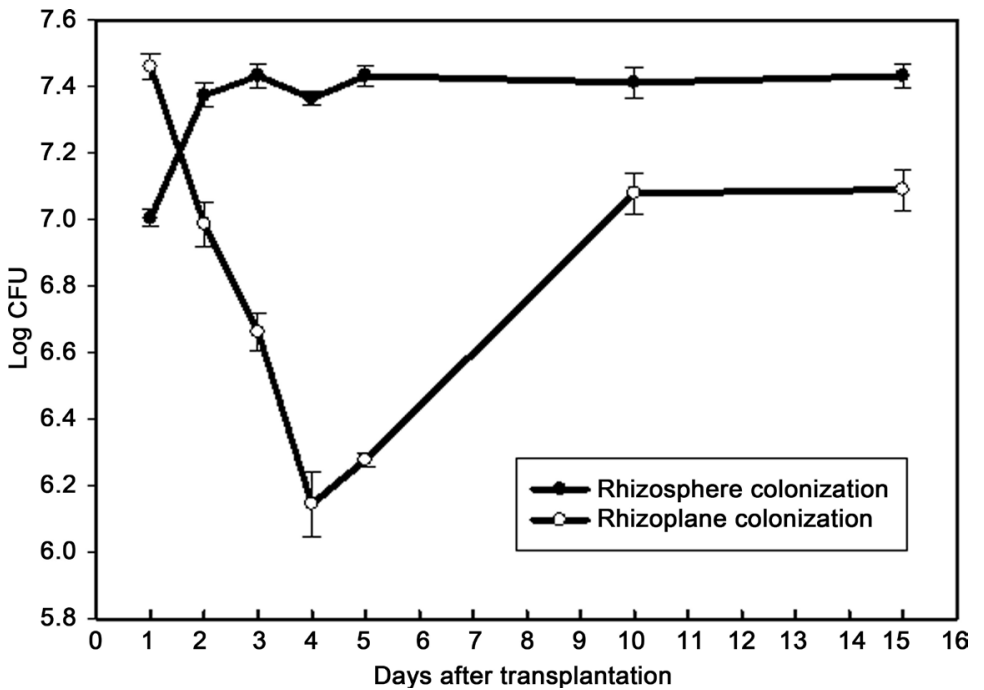

Figure 6. Rhizoplane and rhizosphere colonization by Pseudomonas entomophila FAP1 after different days of transplantation under soil microcosm. 
15 days after transplantation and we found that after three days of transplantation, pre-formed biofilm on the rhizoplane was drastically switched over from the root surface to the rhizosphere as depicted in Figure 6. The strain Pseudomonas entomophila FAP1, after 5 days after transplantation there was reverse back to the rhizoplane from the rhizosphere. Rhizosphere colonization of the test strain exists in the significant number 7.5 Log "CFU/gm", of soil in the rhizosphere up to 15 days after transplantation (DAT).

\section{Discussion}

Use of bioinoculant for promoting plant growth and protecting plant health is an integral part of sustainable crop production. Efficacy of bacterial inoculants on crop production depends upon the complex process of plant-microbe interaction and environmental factors [28]. Successful rhizosphere colonization by bacterial inoculants and expression of PGP traits including plant growth regulators is one of the major factors for plant growth promotion. Determination of the role of biofilm development by rhizobacteria in association with plants surface is the current topic under investigation [29] [30] [31] [32]. The intrinsic ability of bacteria to form biofilm in vitro and in association with plant root varied as reported by [33]. Understanding of rhizobacterial biofilm in the rhizosphere and their interaction to plant roots are still in the age of infancy. The natural interaction among the bacterial population and with plant roots in the natural soil system is predominantly in biofilm mode rather than a planktonic mode of lifestyle and these interactions may be positive or negative [2] [34] [35]. In this study, we have selected a Pseudomonas entomophila FAP1 strain after primary screening based on their multifarious PGP traits, tolerance to abiotic stress, biofilm development and biofilm-associated functions such as EPSs, alginate, swimming and swarming motility and cell surface hydrophobicity of the FAP1 has studied. Pseudomonas entomophila strain (FAP1) produced multifarious PGP traits, tolerate to abiotic stress and have the ability to form a strong biofilm. This combination of traits is expected to increase the plant growth under abiotic stress and protect the plant health by suppressing the pathogen. Further, the bacterium showed strong biofilm development ability in vitro.

Based on the above in vitro multifarious PGP traits, abiotic stress tolerance, biocontrol activity and biofilm development, we further investigated biofilm formation on a glass surface using 12 well tissue culture plates. This PGPR strain formed a strong biofilm. Such strong biofilm formation on the glass surface was demonstrated in other soil bacteria by [34]. We further investigated the behaviours of the FAP1 on ten days old wheat seedling root surface on the adherence and development of microcolonies/biofilm. The findings of root SEM analysis revealed that FAP1 strain adhered on the root surface and establish biofilm. However, this culture occupied root surface spatially separated as well as at a different portion of the root surface. [36] [37], observed that bacterial colonization and biofilm formation was important for the plant growth and protection 
against phytopathogenic fungi in peanut plant. Our findings of biofilm formation on the wheat root surface by FAP1 are probably the first report on PGPR strain. In a separate experiment, we have transplanted the treated seedling of wheat by FAP1 isolate in sterile soil microcosm. The soil microcosm was maintained up to 15 days in climate-controlled growth chamber. Colonization of wheat rhizosphere as well as rhizoplane in treated seedling of wheat with FAP1 demonstrated its ability to survive, adjust and recolonize the rhizosphere/rhizoplane area with $15^{\text {th }}$ days of transplantation of seedling in soil microcosm. A similar observation was revealed by [38]. However, PGPR are effective in colonizing the plant root and further multiply into microcolonies or produce biofilm as result of successful plant-microbe interaction and these plant associated biofilms are highly capable of providing protection from external stress, decreasing microbial competition and giving beneficial effects to the host plant supporting growth, yield and crop quality as reported by [39] [40] [41].

\section{Conclusion}

Based on above study it can be concluded that new isolate of PGPR with desired multifarious activity could be obtained through selective screening and biofilm development by such strain seems to be clear advantages for survival and rhizosphere colonization for enhanced plant growth. However, further experimentation is needed under natural soil system for practical exploitation in crop production/protection.

\section{Acknowledgements}

One of the authors FA Ansari is highly grateful to the University Grant Commission, New Delhi, India, for providing financial assistance in the form of MAN-JRF fellowship. The author is also thankful to University Sophisticated Instrumentation Facility (USIF), Aligarh Muslim University, Aligarh and Macrogen Inc., Seoul, South Korea for respective analysis.

\section{Conflict of Interest}

The authors declare that they have no conflict of interest.

\section{References}

[1] Angus, A.A. and Hirsch, A.M. (2013) Biofilm Formation in the Rhizosphere: Multispecies Interactions and Implications for Plant Growth. In: de Bruijn, F.J., Ed., Molecular Microbial Ecology of the Rhizosphere, Wiley, New York, Vol. 1 \& 2, 701-712.

[2] Rao, D., Webb, J.S. and Kjelleberg, S. (2005) Competitive Interactions in Mixed-Species Biofilms Containing the Marine Bacterium Pseudoalteromonas tunicata. Applied and Environmental Microbiology, 71, 1729-1736. https://doi.org/10.1128/AEM.71.4.1729-1736.2005

[3] Ryu, C.M., Farag, M.A., Hu, C.H., Reddy, M.S., Kloepper, J.W. and Paré, P.W. (2004) Bacterial Volatiles Induce Systemic Resistance in Arabidopsis. Plant Physi- 
ology, 134, 1017-1026. https://doi.org/10.1104/pp.103.026583

[4] Kloepper, J.W., Leong, J., Teintze, M. and Schroth, M.N. (1980) Enhancing Plant Growth by Siderophores Produced by Plant Growth-Promoting Rhizobacteria. Nature, 286, 885-886. https://doi.org/10.1038/286885a0

[5] Ahmad, F., Ahmad, I. and Khan, M.S. (2008) Screening of Free-Living Rhizospheric Bacteria for Their Multiple Plant Growth Promoting Activities. Microbiological Research, 163, 173-181. https://doi.org/10.1016/j.micres.2006.04.001

[6] Bernard, R.G. (2012) Plant Growth-Promoting Bacteria: Mechanisms and Applications. Scientifica, 2012, Article ID: 963401. https://doi.org/10.6064/2012/963401

[7] Burmølle, M., Kjøller, A. and Sørensen, S.J. (2012) An Invisible Workforce: Biofilms in the Soil. In: Lear, G. and Lewis, G., Eds., Microbial Biofilms-Current Research and Applications, Caister Academic Press, Norfolk, 61-72.

[8] Davey, M.E. and O’toole, G.A. (2000) Microbial Biofilms: From Ecology to Molecular Genetics. Microbiology and Molecular Biology Reviews, 64, 847-867. https://doi.org/10.1128/MMBR.64.4.847-867.2000

[9] Jefferson, K.K. (2004) What Drives Bacteria to Produce a Biofilm? FEMS Microbiology Letters, 236, 163-173. https://doi.org/10.1111/j.1574-6968.2004.tb09643.x

[10] Sørensen, S.J., Bailey, M., Hansen, L.H., Kroer, N. and Wuertz, S. (2005) Studying Plasmid Horizontal Transfer in Situ: A Critical Review. Nature Review of Microbiology, 3, 700-710. https://doi.org/10.1038/nrmicro1232

[11] Normander, B. and Prosser, J.I. (2000) Bacterial Origin and Community Composition in the Barley Phytosphere as A Function of Habitat and Pre-Sowing Conditions. Applied and Environmental Microbiology, 66, 4372-4377. https://doi.org/10.1128/AEM.66.10.4372-4377.2000

[12] Singh, A., Jain, A., Sarma, B.K., Upadhyay, R.S. and Singh, H.B. (2014) Rhizosphere Competent Microbial Consortium Mediates Rapid Changes in Phenolic Profiles in Chickpea During Sclerotium Rolfsii Infection. Microbiological Research, 169, 353-360. https://doi.org/10.1016/j.micres.2013.09.014

[13] Lee, K.W.K., Periasamy, S., Mukherjee, M., Xie, C., Kjelleberg, S. and Rice, S.A. (2014) Biofilm Development and Enhanced Stress Resistance of a Model, Mixed-Species Community Biofilm. The ISME Journal, 8, 894-907. https://doi.org/10.1038/ismej.2013.194

[14] Brick, J.M., Bostock, R.M. and Silverstone, S.E. (1991) Rapid In Situ Assay for Indole Acetic Acid Production by Bacteria Immobilized on Nitrocellulose Membrane. Applied and Environmental Microbiology, 57, 535-538.

[15] Loper, J.E. and Scroth, M.N. (1986) Influence of Bacterial Sources on Indole-3-Acetic Acid on Root Elongation of Sugarbeet. Phytopathology, 76, 386-389. https://doi.org/10.1094/Phyto-76-386

[16] Dye, D.W. (1962) The Inadequacy of the Usual Determinative Tests for the Identification of Xanthomonas spp. New Zealand Journal of Science, 5, 393-416.

[17] Lorck, H. (1948) Production of Hydrocyanic Acid by Bacteria. Physiologia Plantarum, 1, 142-146. https://doi.org/10.1111/j.1399-3054.1948.tb07118.x

[18] Reeves, M.W., Pine, L., Neilands, J.B. and Balows, A. (1983) Absence of Siderophore Activity in Legionella Species Grown in Iron-Deficient Media. Journal of Bacteriology, 154, 324-329.

[19] Gaur, A.C. (1990) Physiological Functions of Phosphate Solubilizing Micro-Organisms. In: Gaur, A.C., Ed., Phosphate Solubilizing Micro-Organisms as Biofertilizers, Omega Scientific Publishers, New Delhi, 16-72. 
[20] Riungu, G.M., Muthorni, J.W., Narla, R.D., Wagacha, J.M. and Gathumbi, J.K. (2008) Management of Fusarium Head Blight of Wheat and Deoxynivalenol Accumulation Using Antagonistic Microorganisms. Plant Pathology Journal, 7, 13-19. https://doi.org/10.3923/ppj.2008.13.19

[21] Mody, B.R., Bindra, M.O. and Modi, V.V. (1989) Extracellular Polysaccharides of Cowpea Rhizobia: Compositional and Functional Studies. Archives of Microbiology, 153, 38-42. https://doi.org/10.1007/BF00277538

[22] Wozniak, D.J., Wyckoff, T.J.O., Starkey, M., Keyser, R., Azadi, P., O’Toole, G.A. and Parsek, M.R. (2003) Alginate Is Not a Significant Component of the Extracellular Polysaccharide Matrix of PA14 and PAO1 Pseudomonas aeruginosa Biofilms. Proceedings of the National Academy of Sciences of the United States of America, 100, 7907-7912. https://doi.org/10.1073/pnas.1231792100

[23] Rosenberg, M., Gutnick, D. and Rosenberg, E. (1980) Adherence of Bacteria to Hydrocarbons: A Simple Method for Measuring Cell-Surface Hydrophobicity. FEMS Microbiology Letters, 9, 29-33. https://doi.org/10.1111/j.1574-6968.1980.tb05599.x

[24] Adler, J. (1966) Chemotaxis in Bacteria. Science, 153, 708-716. https://doi.org/10.1126/science.153.3737.708

[25] OToole, G.A. and Kolter, R. (1998) Flagellar and Twitching Motility Are Necessary for Pseudomonas aeruginosa Biofilm Development. Molecular Microbiology, 30, 295-304. https://doi.org/10.1046/j.1365-2958.1998.01062.x

[26] Simons, M., van der Bij, A.J., Brand, I., de Weger, L.A., Wijffelman, C.A. and Lugtenberg, B.J.J. (1996) Gnotobiotic System for Studying Rhizosphere Colonization by Plant Growth-Promoting Pseudomonas Bacteria. Molecular Plant-Microbe Interaction, 9, 600-607. https://doi.org/10.1094/MPMI-9-0600

[27] Friedman, L. and Kolter, R. (2004) Genes Involved in Matrix Formation in Pseudomonas aeruginosa PA14 Biofilms. Molecular Microbiology, 51, 675-690. https://doi.org/10.1046/j.1365-2958.2003.03877.x

[28] Wu, C.H., Bernard, S.M., Andersen, G.L. and Chen, W. (2009) Developing Microbe-Plant Interactions for Applications in the Plant-Growth Promotion and Disease Control, Production of Useful Compounds, Remediation and Carbon Sequestration. Microbial Biotechnology, 2, 428-440. https://doi.org/10.1111/j.1751-7915.2009.00109.x

[29] Albareda, M., Dardanelli, M.S., Sousa, C., Megias, M., Temprano, F. and Rodríguez-Navarro, D.N. (2006) Factors Affecting the Attachment of Rhizospheric Bacteria to Bean and Soybean Roots. FEMS Microbiology Letters, 259, 67-73. https://doi.org/10.1111/j.1574-6968.2006.00244.x

[30] Danhorn, T. and Fuqua, C. (2007) Biofilm Formation by Plant-Associated Bacteria. Annual Review of Microbiology, 61, 401-422. https://doi.org/10.1146/annurev.micro.61.080706.093316

[31] Fujishige, N.A., Lum, M.R., De Hoff, P.L., Whitelegge, J.P., Faull, K.F. and Hirsch, A.M. (2008) Rhizobium Common Nod Genes Are Required for Biofilm Formation. Molecular Microbiology, 67, 504-515. https://doi.org/10.1111/j.1365-2958.2007.06064.x

[32] Ansari, F.A., Jafri, H., Ahmad, I. and Abulreesh, H. (2017) Factors Affecting Biofilm Formation in in Vitro and in the Rhizosphere. In: Ahmad, I. and Husain, F.M., Eds., Biofilms in Plant and Soil Health, Wiley, New York, 275-290. https://doi.org/10.1002/9781119246329.ch15

[33] Altaf, M.M. and Ahmad, I. (2017) In Vitro and in Vivo Biofilm Formation by Azotobacter Isolates and Its Relevance to Rhizosphere Colonization. Rhizosphere, 3, 
138-142. https://doi.org/10.1016/j.rhisph.2017.04.009

[34] Burmølle, M., Ren, D., Bjarnsholt, T. and Sørensen, S.J. (2014) Interactions in Multispecies Biofilms: Do They Actually Matter? Trends in Microbiology, 22, 84-91. https://doi.org/10.1016/j.tim.2013.12.004

[35] Ren, D., Madsen, J.S., Sørensen, S.J. and Burmølle, M. (2015) High Prevalence of Biofilm Synergy among Bacterial Soil Isolates in Cocultures Indicates Bacterial Interspecific Cooperation. The ISME Journal, 9, 81-89. https://doi.org/10.1038/ismej.2014.96

[36] Timmusk, S. and Wagner, E.G.H. (1999) The Plant-Growth-Promoting Rhizobacterium Paenibacillus polymyxa Induces Changes in Arabidopsis Thaliana Gene Expression: A Possible Connection between Biotic and Abiotic Stress Responses. $\mathrm{Mo}-$ lecular Plant-Microbe Interaction, 12, 951-959.

https://doi.org/10.1094/MPMI.1999.12.11.951

[37] Timmusk, S., Grantcharova, N. and Wagner, E.G.H. (2005) Paenibacillus polymyxa Invades Plant Roots and Forms Biofilms. Applied and Environmental Microbiology, 71, 7292-7300. https://doi.org/10.1128/AEM.71.11.7292-7300.2005

[38] Islam, S., Akanda, A.M., Prova, A., Islam, M.T. and Hossain, M.M. (2016) Isolation and Identification of Plant Growth Promoting Rhizobacteria from Cucumber Rhizosphere and Their Effect on Plant Growth Promotion and Disease Suppression. Frontiers in Microbiology, 6, 1360. https://doi.org/10.3389/fmicb.2015.01360

[39] Ramey, B.E., Koutsoudis, M., von Bodman, S.B. and Fuqua, C. (2004) Biofilm Formation in Plant-Microbe Associations. Current Opinion in Microbiology, 7, 602-609. https://doi.org/10.1016/j.mib.2004.10.014

[40] Saleh-Lakha, S. and Glick, B.R. (2006) Plant Growth-Promoting Bacteria. Modern Soil Microbiology, 503-520.

[41] Lugtenberg, B. and Kamilova, F. (2009) Plant-Growth-Promoting Rhizobacteria. Annual Review of Microbiology, 63, 541-556.

https://doi.org/10.1146/annurev.micro.62.081307.162918 